\title{
METAPHYSIAL DYSOSTOSIS, TYPE SCHMID
}

\author{
BY \\ C. E. DENT and I. C. S. NORMAND \\ Metabolic Ward and Paediatric Department, University College Hospital, London
}

(RECEIVED FOR PUBLICATION APRIL 6, 1964)

It is interesting to note the way in which medical knowledge has developed over the years with regard to diseases superficially akin to classical rickets. The first stage followed as a result of the disappearance, owing to the improved knowledge of nutrition, of classical rickets as a common source of bony deformity. This led to the clearer recognition of the remaining 'resistant' forms of rickets, mostly due to renal glomerular disease, to steatorrhoea, or to various hereditary renal tubular dysfunctions. All these resemble classical rickets biochemically, histologically, and radiologically, and heal with very large doses of vitamin $D$. Now it has become apparent that there remains a further group of diseases that superficially resemble rickets but do not fit into the categories of 'resistant' rickets, since they lack the characteristic biochemical changes, and in particular they show no beneficial response to vitamin $D$ in any dosage. It is tempting to describe examples of this group as having a form of 'chondrodystrophy' or 'developmental defect' and to put them aside as incurable and likely to be unproductive as a source of theoretical knowledge. We prefer to believe, however, that if further homogeneous diseases can be defined from this group, and especially if genetic factors can be implicated, then a good case can be made for assuming that there must be a basic biochemical disorder, presumably an inborn error of metabolism. Study of such cases could, therefore, be rewarding if new enzymic functions could be discovered followed by new lines of treatment.

We describe here five patients with a disorder closely resembling rickets clinically and radiologically but without the usual biochemical changes and without the usual response to vitamin $\mathrm{D}$.

\section{Case Histories}

Case 1. Sharne $\mathrm{H}$. was admitted at 2 years of age to the Metabolic Ward, University College Hospital, for investigation of her short stature and of changes in her long bones resembling rickets.

The pregnancy and delivery were uncomplicated and her birth weight was $8 \mathrm{lb} .8 \mathrm{oz}$. (3.94 kg.). Mental and motor development during infancy were normal but there had been a tendency to repeated spells of vomiting after meals. There had been no unusual variation in her diet except that the addition of sodium citrate $2 \mathrm{~g}$. daily appeared to stop her vomiting.

At the age of 1 year she weighed $20 \mathrm{lb} .(9 \cdot 1 \mathrm{~kg}$.) and was attempting to walk, but over the next six months she became increasingly unwilling to stand and appeared to be losing some power in her legs. During this time there was insignificant weight gain. At 18 months of age the parents first noticed swellings of her ribs. She was referred to Dr. J. Burkinshaw who in addition to the expanded costochondral junctions noted also the enlargement of the ends of the long bones. The plasma bicarbonate was $31.4 \mathrm{vol} .{ }^{\circ}$ o $(14 \mathrm{mM} / \mathrm{l}$.$) in the presence$ of a urinary $p \mathrm{H}$ of $7 \cdot 0$, and it was considered that the child might have rickets secondary to renal acidosis.

She was treated with oral vitamin D, 3,000 to 12,000 i.u. daily and had a course of ultraviolet light; but her bone changes remained unaltered and she was referred to U.C.H.

FAMILY History. The father had had a nephrectomy for renal calculi which were stated to have been composed of uric acid. The mother and the patient's two elder sisters had always been well. All were of normal stature.

EXamination. She was a lively girl aged 24 months, of normal mental development but very short stature (Fig. 1a and b). Measurements: height, 31 in. $(79 \mathrm{~cm}$.$) ;$ upper segment, 19 in. $(48 \mathrm{~cm}$.); lower segment, 12 in. (30.8 cm.); span, 29 in. (74 cm.); weight, $24 \mathrm{lb} .(10 \cdot 9 \mathrm{~kg}$.); and head circumference, 19.75 in. $(50 \cdot 2 \mathrm{~cm}$.). Her forehead had some prominence, but her facial appearance had no characteristic features. The anterior fontanelle was closed and tooth eruption was normal.

There was shortening of her limbs especially of the proximal segments with anterior and lateral bowing of the femora and to a lesser extent of the tibiae. The ends of the long bones were expanded as also were the costochondral junctions. There was an excessive lumbar lordosis and she had a pronounced waddling gait. The hands and feet appeared normal.

Apart from the skeletal system no abnormality was found on examination and her blood pressure was $85 / 60$ $\mathrm{mm} . \mathrm{Hg}$. 


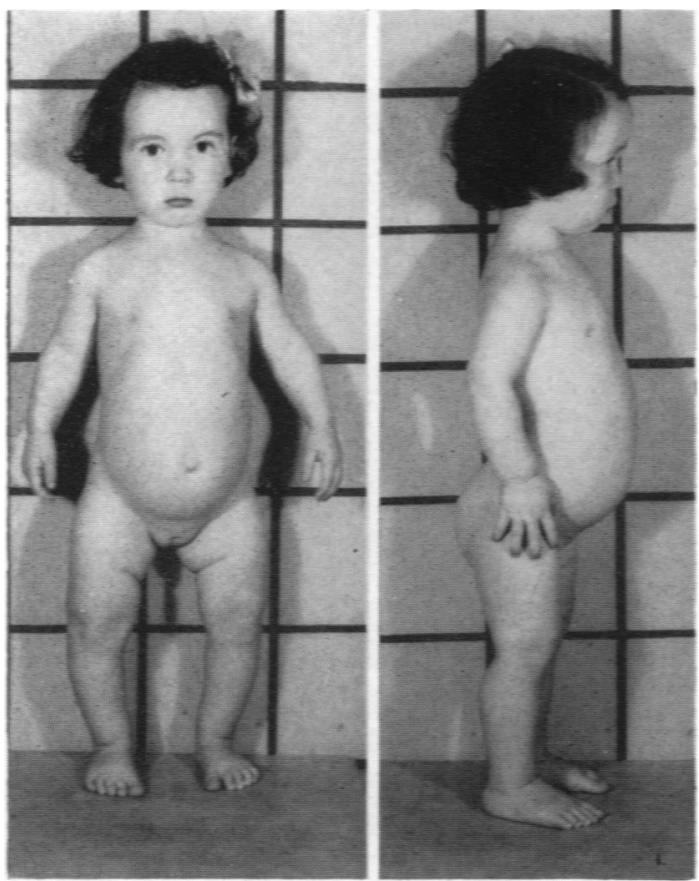

Fig. 1 a and b. - Sharne H. (Case 1), aged 2 years.

Radological InVestigations. The skull and spine were normal. There were striking changes at the ends of the long bones, the epiphyses throughout being normal. Typical changes are seen in her lower limbs (Fig. 2): the epiphysial plates are unusually wide, the ends of the metaphyses are ragged and in the upper end of the fibulae are cupped and expanded. However, there is considerable density in the metaphyses which resemble healing rather than active rickets. The bone shafts are strongly built with normal corticomedullary differentiation and with normal trabecular structure. The shortening and smooth bowing suggests a long-standing disorder, the bones having grown slowly into this shape and not having bent after growth. The immediate and long-term followup excluded the possibility of healing rickets as the bones did not heal but continued to grow slowly manifesting the same appearance.

BLoOd Count. Hb, 13.6 g.' $100 \mathrm{ml}$.; white blood cells, 8,100 with normal differential.

URINE. No protein, no sugar, no pyuria, cultures sterile. Maximum urea concentration $4.05 \mathrm{~g} . / 100 \mathrm{ml}$.; maximum specific gravity 1,033 ; urinary cakcium excretion $96 \mathrm{mg}$. a day; phosphorus excretion $355 \mathrm{mg}$. a day.

BloOd Chemistry. Plasma sodium, $145 \mathrm{mEq}$ l.; potassium, $4.25 \mathrm{mEq}$; chloride, $106 \mathrm{mEq}$; total $\mathrm{CO}$, $17.9 \mathrm{mEq}$; urea, $36 \mathrm{mg}$./ $100 \mathrm{ml}$.; serum calcium, 11.0 and $9.9 \mathrm{mg}$. $100 \mathrm{ml}$.; phosphorus, $5.4 \mathrm{mg}$./100 ml.; alkaline phosphatase, 24 K.A. units $/ 100 \mathrm{ml}$.
Calcium and Phosphorus Studies. Cakcium balances in six-day collection periods were carried out after six-day equilibration to a constant diet similar to her previous home intake. The first period showed that on a daily intake of $1,145 \mathrm{mg}$. of Ca she excreted $695 \mathrm{mg}$. in the faeces and $113 \mathrm{mg}$. in the urine. This was considered normal. The urine collections only were continued while she was taking $50 \mathrm{mEq}$ of $\mathrm{NH}_{4} \mathrm{Cl}$ a day for four days and then full collections were obtained while she was taking $50 \mathrm{mEq}$ of $\mathrm{NaHCO}_{3}$ for another six-day period. No marked changes in calcium excretion occurred without and with alkali. On the $\mathrm{NH}_{4} \mathrm{Cl}$ the urine $\mathrm{pH}$ fell to $5 \cdot 1$ with a normal rise in ammonium and calcium output. There were only small changes throughout in plasma electrolytes and she tolerated the two drugs well. A final six-day period on $0.3 \mathrm{mg}$. calciferol a day likewise produced no marked changes. We concluded that there

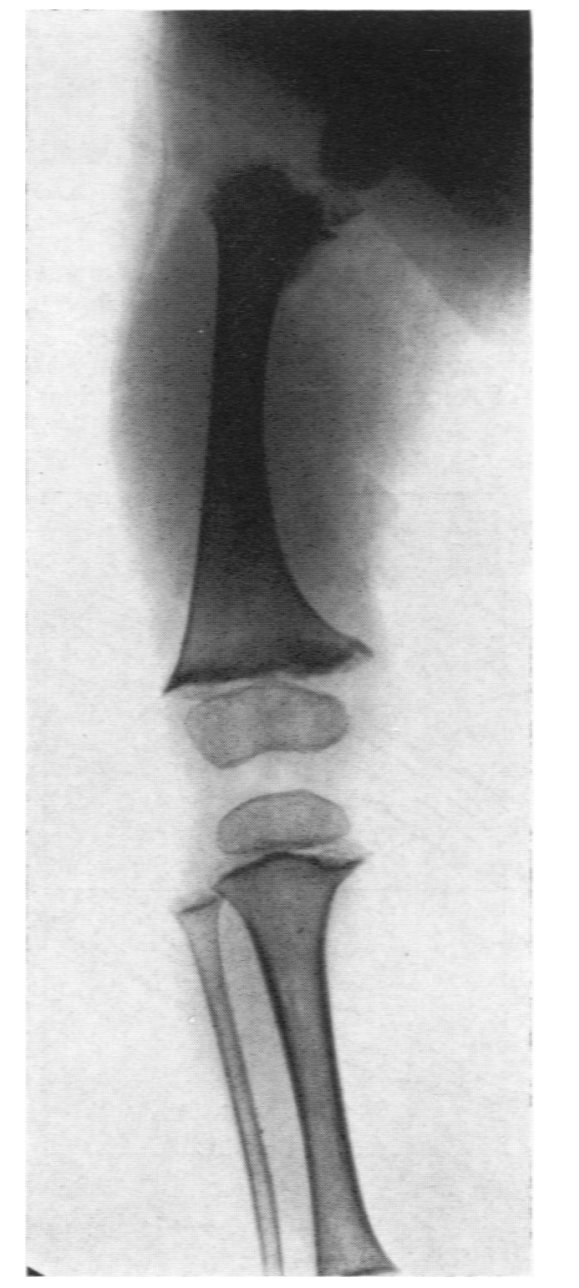

FKG. 2.-Sharne H. (Case 1), aged 2 years. Radiograph of lower limb. 

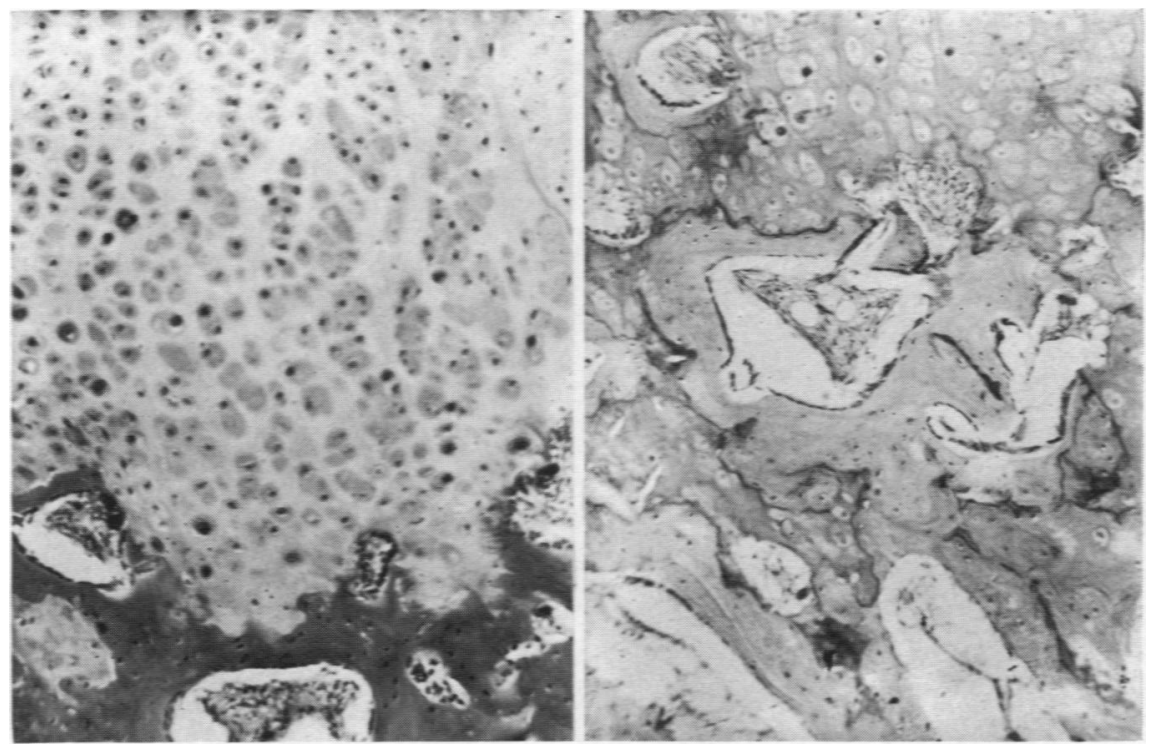

Fig. 3a and b.-Sharne H. (Case 1). Bone biopsy near epiphysial plate (see text). Lower end of femur. ( $\times$ 40.)

was no evidence of renal acidosis, nor of any response to the dose of vitamin $D$ given, this being a dose that would rapidly cure a patient with classical rickets.

A phosphate inulin infusion test was carried out by the method of Anderson (1955). Her glomerular filtration

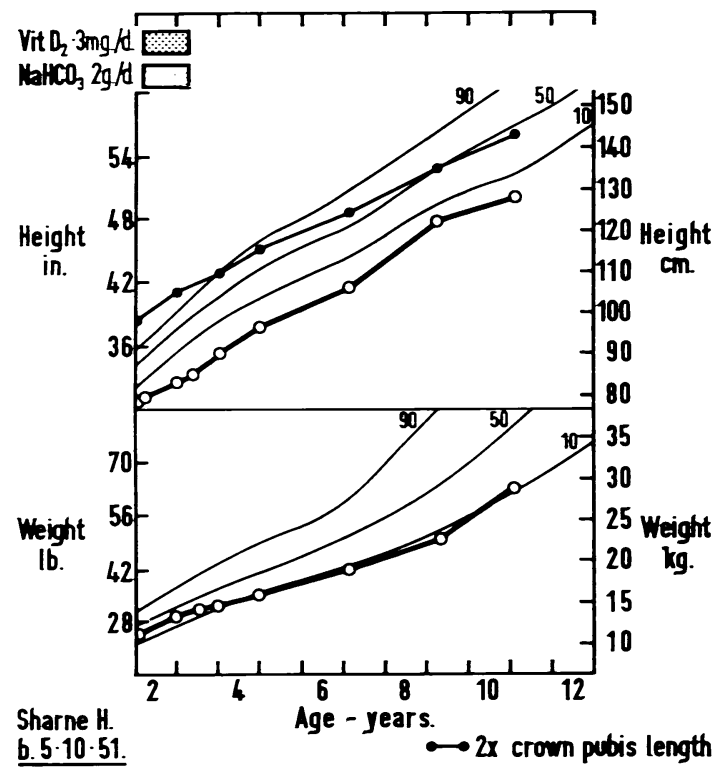

Fig. 4.-Sharne H. (Case 1). Growth chart. Twice the trunk length is also plotted to show that this, a measure of her true height if her legs were not so short. is relatively normal. rate (uncorrected) was $53 \mathrm{mg} . / \mathrm{min}$. calculated from the inulin data and $43 \mathrm{ml}$./min. calculated from $\mathrm{PO}_{4}$ data. Renal $\mathrm{PO}_{4}$ threshold was $4.7 \mathrm{ml} . / 100 \mathrm{ml}$, and $\mathrm{TmPO}_{4}$ $1 \cdot 1 \mathrm{mg}$. $/ \mathrm{min}$., both considered normal for a child of this age, though we have very little data for comparison in this age-group and have to base our opinion by a comparison with adults. We concluded that there was no renal

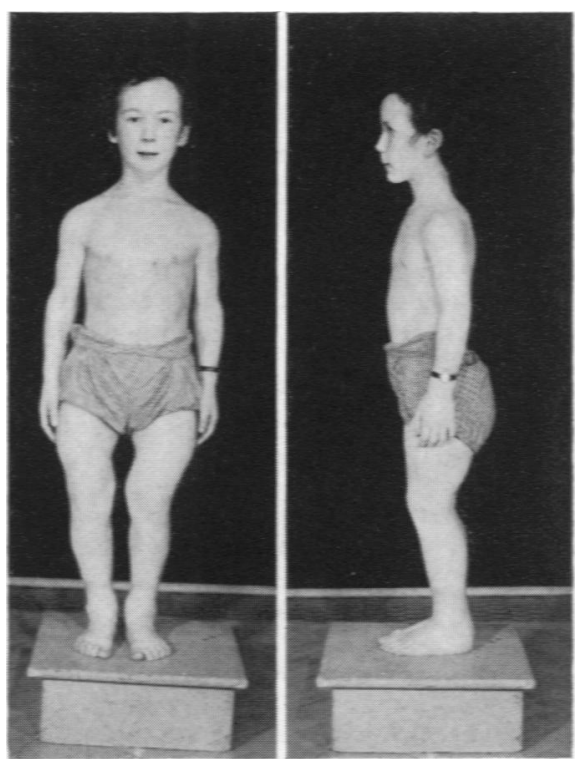

FiG. Sa and b.-Sharne H. (Case 1), aged 11 years. 


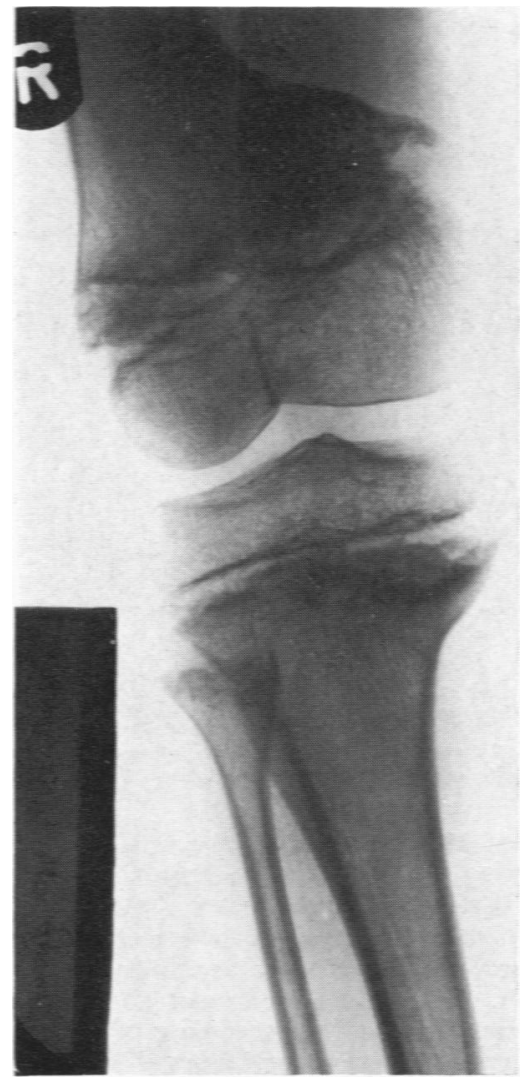

FrG. 6.-Sharne H. (Case 1), aged 11 years. Radiograph of bones. Note the continued resemblance to 'healing rickets'. There are no Harris lines in the shaft to sugest previous variable rates of bone growth.

tubular reabsorption defect for $\mathrm{PO}_{4}$ as occurs in most cases of 'resistant rickets'.

BюPsy. This was taken from the lower end of the right femur when she was 3 years and 8 months (Fig. $3 a$ and $b$ ). It was reported on by Dr. H. A. Sissons as follows: 'Endochondral ossification on the growing surface of the epiphyseal plate is disorganized. Cartilage columns are irregular and there is failure of maturation and cakcification of the tissue with the formation of masses of abnormal and uncalcified cartilage matrix. Some bony replacement of the abnormal cartilage is occurring but at a greatly retarded rate.'

'The bone tissue itself, both in the epiphyses and metaphyses, is more normal. No excess of osteoid is present and there is no osteitis fibrosa. The above findings are consistent with metaphyseal dysostosis.'

Treatment and Progress. On leaving hospital she was treated with vitamin $D_{2} 0.3 \mathrm{mg}$. daily and sodium bicarbonate $2 \mathrm{~g}$. daily for 14 months. There was no change in the clinical or radiological appearances, and this therapy was then abandoned.

Because of progressive deformity of her legs, bilateral manual osteoclases of tibiae were performed when she was 3 years 8 months by Prof. H. J. Seddon. A biopsy (see report above) was obtained at the same time. The bones healed normally.

Following operation the gait was greatly improved though there still tends to be some waddle.

She remains in excellent general health and has grown steadily, and the chart (Fig. 4) and photos (Fig. 5a and b) illustrate that there is now less disproportionate retardation of limb growth. Subsequent bone radiographs show identical appearances to those originally taken if due allowance for growth is made (Fig. 6).

She now attends boarding school and takes part in all games.

Case 2. Susan $P$. was seen at the age of 8 years when she was under the care of Sir Wilfrid Sheldon at The Hospital for Sick Children, and we are most grateful for his permission to publish details of this case. She was the first child in the family and had been delivered by caesarean section because of the mother's contracted pelvis. The birth weight was $8 \mathrm{lb} .4 \mathrm{oz}$. (3.7 kg.). She was breast fed for nine months and then weaned on to a normal mixed feeding régime. One teaspoon daily of cod liver oil was started at 1 month, increasing to $2 \frac{1}{2}$ teaspoons at $\mathbf{3 0}$ months.

Her early development was normal and she was standing on her own at 12 months. At 21 months, however, her hips were noted to be 'stiff', and orthopaedic treatment in a frame was commenced at another hospital. Her gait was said to be improved as a result but there was progressive bowing of her legs and retardation of growth. She was accordingly admitted to hospital on two further occasions before the age of 5 years. The radiographs were interpreted as showing active rickets, and she was treated with doses of vitamin D varying from 20,000 units to 150,000 units daily. These produced hypercalcaemia on five separate occasions accompanied by anorexia and vomiting, the serum cakium level at one point rising to $16.5 \mathrm{mg} . / 100 \mathrm{ml}$. Subsequently she was able to tolerate calciferol 700,000 units i.m. weekly and was maintained on this for three years without improvement in her bone changes.

Family History. The mother reputedly had rickets as a child and was treated in a frame from 6 months to 15 months of age. Subsequently she wore irons. Her adult height is 55 in. $(140 \mathrm{~cm}$.). The father is normal in stature.

EXAmInAtron. She was a small well-muscled girl aged 8 years (Fig. 7a and b). Height $39 \cdot 25$ in. (100 cm.) and weight $45 \mathrm{lb}$. (20.5 kg.). Her limbs were short, particularly the proximal portions, and there was considerable bowing of her legs with coxa vara. The lumbar lordosis was exaggerated, and she had a waddling gait. The ends of her long bones were expanded and she had a typical rachitic rosary. There was some bossing of her forehead. The other systems were normal and the blood pressure was $100 / 60 \mathrm{~mm} . \mathrm{Hg}$. 

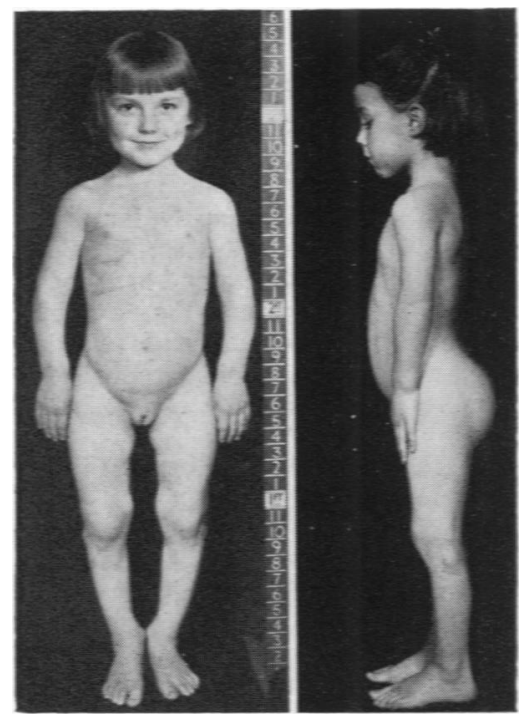

Fig. 7a and b.-_Susan P. (Case 2), aged 8 years.

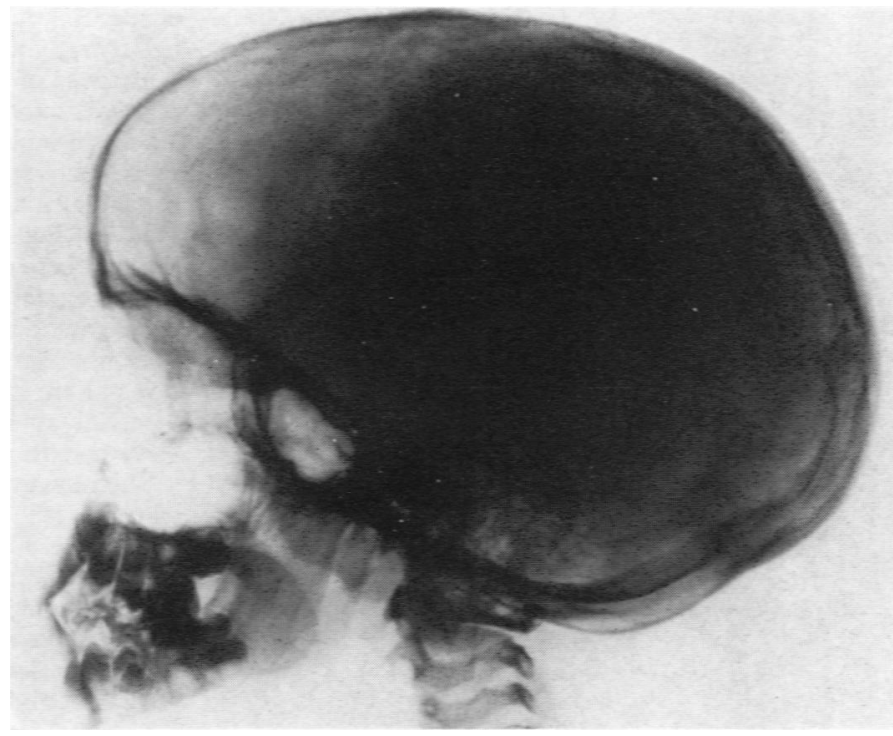

FiG. 8.- Susan P. (Case 2). aged 8 years. The skull radiograph is normal and quite unlike that in achondroplasia.

INVESTIGATIONS. The radiological changes in the bones were in every respect identical to those described in Case 1. Various parts of the skeleton are shown in Figs. 8-12. Note that the more rapidly growing ends of the bones show more abnormal changes. as also occurs in any form of rickets. There were no Looser zones, bone cysts, subperiosteal erosions, or other signs of metabolic bone disease, nor were there abnormalities of bone growth as in achondroplasia. Serum calcium, $10.6 \mathrm{mg} . / 100 \mathrm{ml}$.; inorganic phosphorus, $3.5 \mathrm{mg}$. $100 \mathrm{ml}$.; alkaline phosphatase, $11 \mathrm{~K}$.A. units $/ 100 \mathrm{ml}$.; blood urea, $25 \mathrm{mg}$. $/ 100 \mathrm{ml}$.; plasma bicarbonate, $21 \mathrm{mM} / 1$.

Tubular reabsorption of phosphate was calculated at 137 and $187 \mathrm{mg}$./ hr., the calculated normal for her size being 200-400 mg./hr. Initial calcium and phosphorus balances suggested a raised calcium output but she had very recently been on massive vitamin $D$ therapy. A repeat balance four months later during which time she received 30,000 units of vitamin $D$ daily showed that she was retaining $500 \mathrm{mg}$. calcium daily.

Mother's blood chemistry: serum calcium, $10 \mathrm{mg}$. 100 $\mathrm{ml}$.; inorganic phosphorus, $2.3 \mathrm{mg}$./100 $\mathrm{ml}$.; and alkaline phosphatase, 6 K.A. units $/ 100 \mathrm{ml}$.

Bopsy. A section (Fig. 13) was taken of a costochondral junction at the age of 9 years (Mr. D. J. Waterston). The late Dr. M. Bodian reported as follows: 'The cartilage is hypertrophied and shows excessive degenerative changes. There is no orderly parallel column arrangement of cartilage cells in the zone of provisional calcification and the cells in this area are also hypertrophic. There is a fairly abrupt transition of cartilage into wellcalcified lamellated bone with well-formed trabeculae and Haversian systems and plentiful osteoblasts. There is hardly any osteoid formation. The capillaries and
Frg. 9.-Susan P. (Case 2), aged 8 years. Lateral chest radiograph showing the rib ends which are grossly expanded and cupped. 


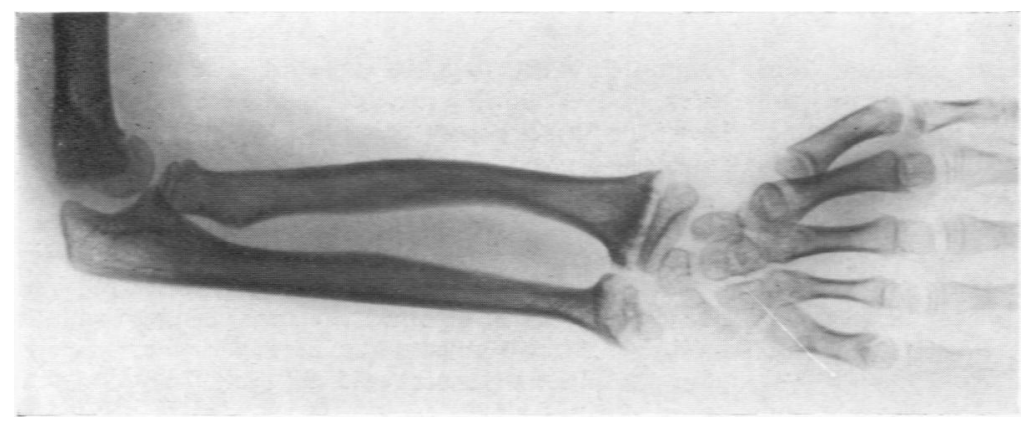

Fig. 10.-Susan P. (Case 2), aged 8 years. Radiograph of forearm, showing gross 'rachitic' changes at wrist. Elbow is normal.

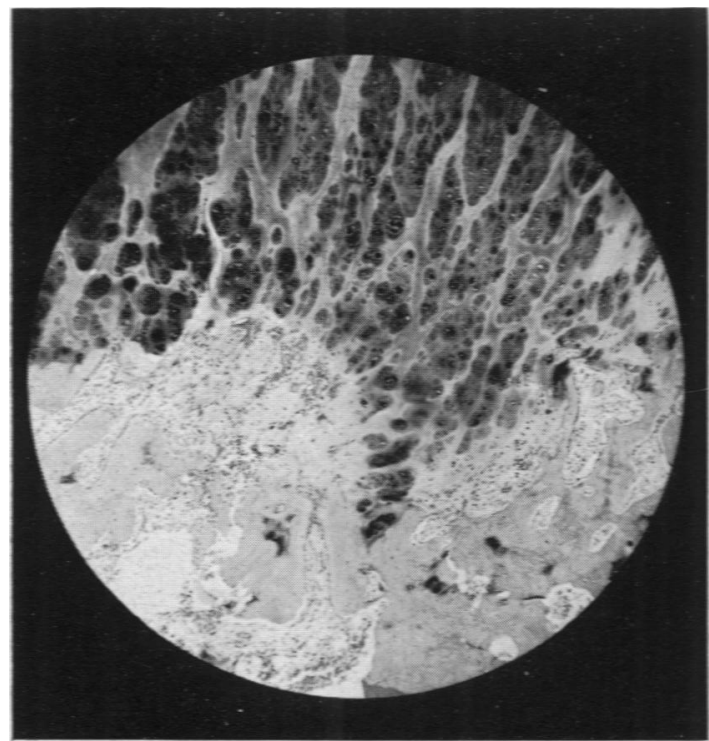

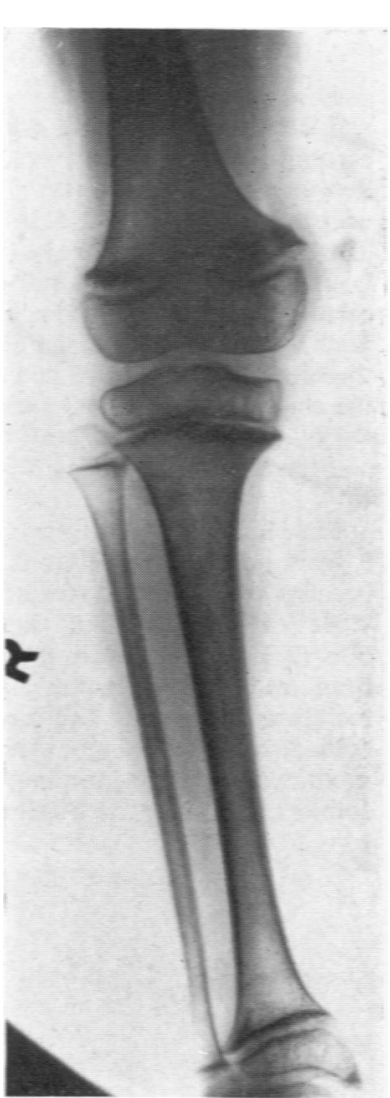

Fig. 12. Susan P. (Case 2), aged 8 years. Radiograph of lower limb.

-Susan P. (Case 2) one biopsy, from costochondral junction (see text). ( $\times 32$.)
Fig. 11.-Susan P. (Case 2), aged 8 years. Radiograph of pelvis.

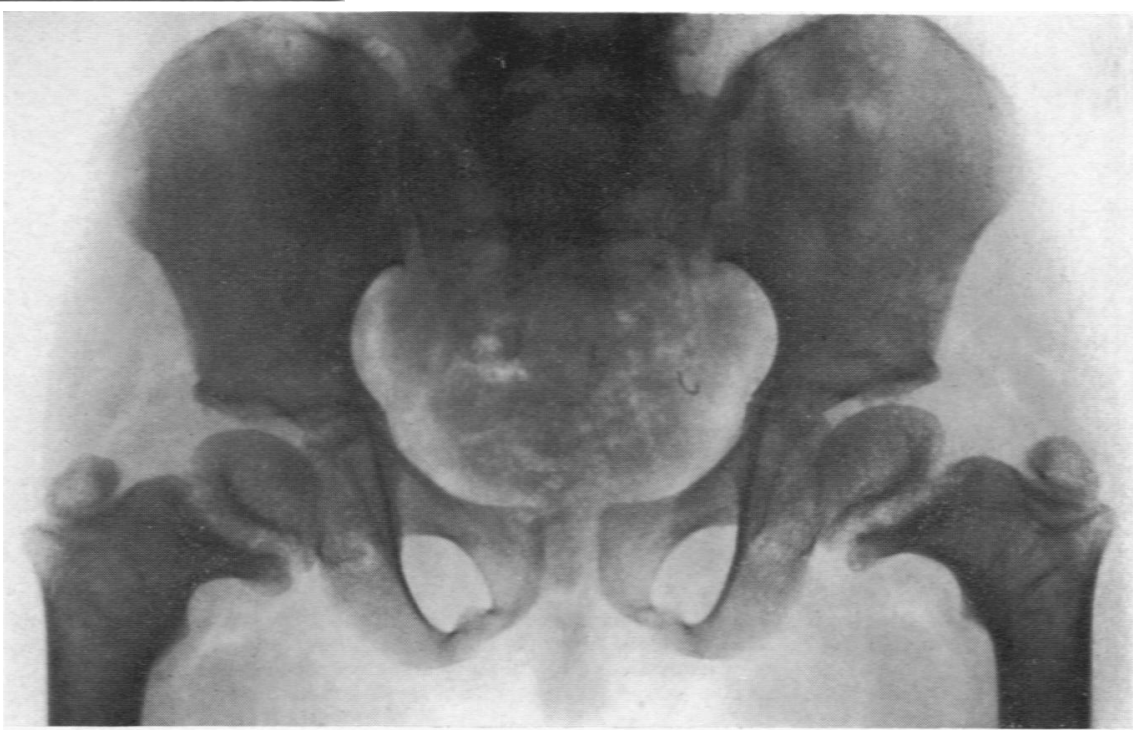


osteoclasts between cartilage and bone are adequate. In active rickets one would expect to see: 1 . Hyperplastic cartilage without orderly column formation. 2. A wide irregular zone of tongues of cartilage intermingled with wide tongues of osteoid. 3. Imperfect calcification of bone. The last two features are not present. Even if this were healing rickets I would still expect the intermingling of cartilage and bone at the transitional zone to persist. Such is not the case and the diagnosis of healing rickets is, therefore, not seriously entertained. I would interpret the changes as indicating a chondrodystrophy.'

Following this biopsy all treatment was discontinued and the child was thriving 3 years later.

Case 3. Marilyn C. was seen at U.C.H. at the age of 5 years having been referred to us by Dr. A. C. Crooke because of a condition resembling rickets.

Her early development was normal, birth weight being $6 \mathrm{lb}$. $(2.7 \mathrm{~kg}$.); but at the age of 18 months, after she had been walking for some months, the parents noted increasing bowing of her legs. She was admitted to an orthopaedic hospital and immobilized in a frame for four months. For some months after this she was in abductive splints and during the whole of this period she was given vitamin $D, 4,000$ to 8,000 units daily, in the form of 'adexolin'. Following this treatment there seems to have been little further bowing of her legs but growth remained slow.

At the age of 4 years and 9 months she was admitted to Little Bromwich General Hospital for investigation of her bone disorder. Normal figures for serum electrolytes, urea, calcium, inorganic phosphorus, and alkaline phosphatase were obtained. There was no aminoaciduria. More detailed studies of renal tubular function gave phosphate clearances of $5 \mathrm{ml}$. and $4 \mathrm{ml} . / \mathrm{min}$. with phosphate/creatinine clearance ratios of 0.31 and 0.25 . Renal response to doses of sodium citrate and ammonium chloride was normal.

She was thought to have a dyschondroplasia of some kird. The father's height was 71 in. $(180 \mathrm{~cm}$.) and the mother's 61 in. $(155 \mathrm{~cm}$.). Two elder sibs were of normal stature and none showed any obvious bony deformities.

Marilyn C. was a short 5-year-old girl; height, 36.5 in. (93 cm.); upper segment, 21 in. $(53 \mathrm{~cm}$.); lower segment, 15.5 in. ( $39 \mathrm{~cm}$.); span 37 in. $(94 \mathrm{~cm}$.). Limbs were short, but this and the slight bowing were appreciably less than in the other cases. She had a waddling gait and her bone ends were expanded.

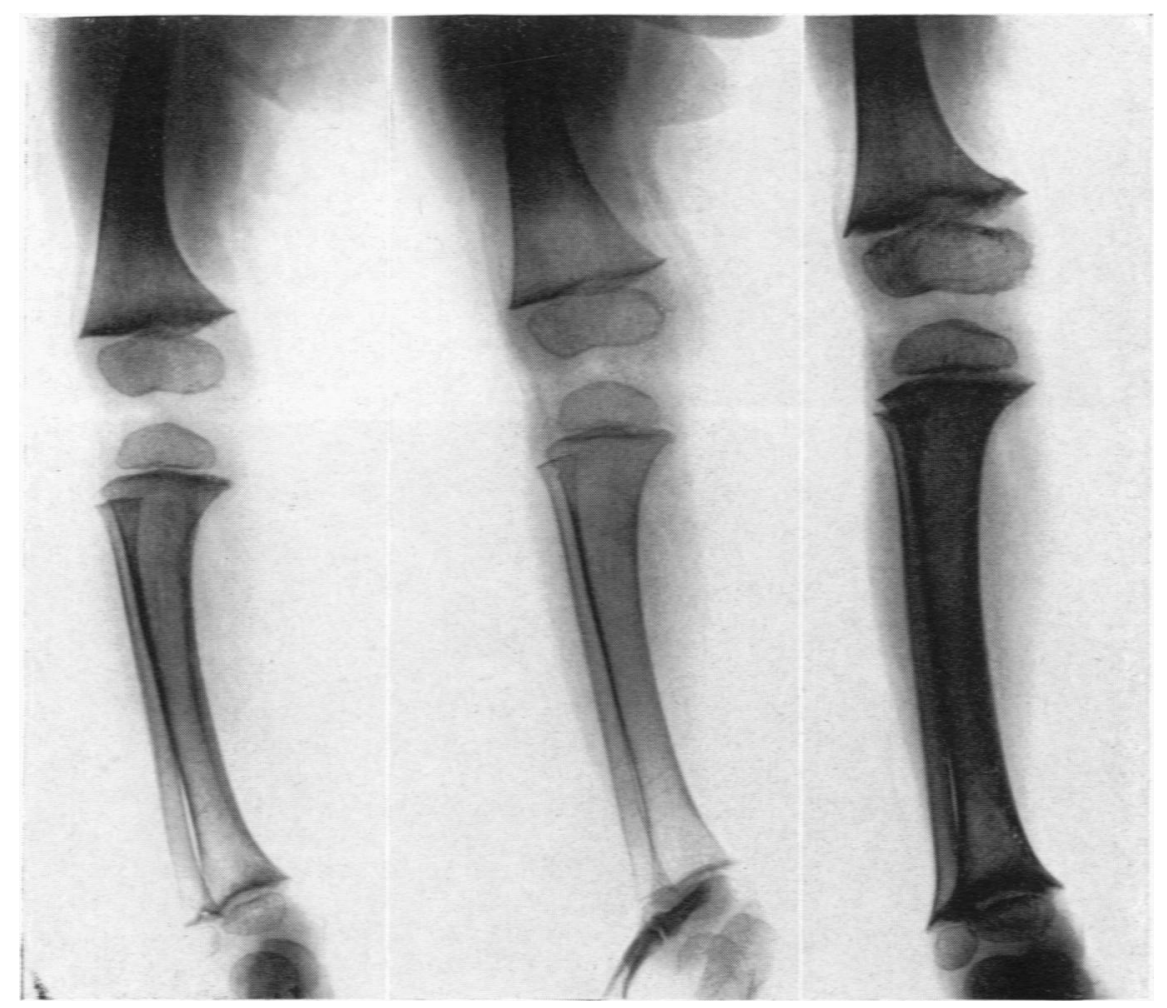

Fig. 14.-Marilyn C. (Case 3). Radiograph of lower limb in Julv 1955. There is a raged appearance of the metaphysis.

Fig. 15.-Marilyn C. (Case 3). Radiograph of lower limb in October 1955. The metaphyses have healed following immobilization. A clear osteoporosis has also developed for the same reason.

Fig. 16.-Marilyn C. (Case 3). Radiograph of lower limb in November 1956. The ragged metaphyses have reappeared following re-mobilization. 
Radiologically she showed the typical metaphysial changes of the previous cases. Review of her previous films, however, showed a striking return to normality of the metaphyses over a three-month period during which she was immobilized in bed, the improvement being noted in both upper and lower limbs. She was then allowed up again, and in spite of 4,000 to 8,000 units of vitamin D daily complete reversion to the original appearances took place (Figs. 14-16).

Serum calcium was $10.3 \mathrm{mg} . / 100 \mathrm{ml}$., inorganic phosphorus $4.4 \mathrm{mg} . / 100 \mathrm{ml}$., alkaline phosphatase 19 K.A. units $/ 100 \mathrm{ml}$., urea $30 \mathrm{mg} . / 100 \mathrm{ml}$. Routine urinalysis and urine chromatography were normal.

It was felt that no further treatment was justified, and the radiological appearances have not significantly altered. At the age of 9 years and 9 months her height was $44 \cdot 75$ in. $(114 \mathrm{~cm}$.), upper segment 24.75 in. $(63 \mathrm{~cm}$.), lower segment 20 in. ( $51 \mathrm{~cm}$.), span 46 in. (117 cm.), weight $46 \cdot 5 \mathrm{lb}$. (21. 1 kg.).

Case 4. Christopher $H$. was seen at the age of 26 months having been referred by Mr. G. K. Rose from the Royal Salop Infirmary for investigation of a rachitic-like condition. During the pregnancy his mother had been treated for a possible tuberculous pulmonary infection. His birth weight was $8 \mathrm{lb} .2 \mathrm{oz} .(3 \cdot 7 \mathrm{~kg}$.) and his subsequent development was normal except that walking was delayed until 19 months when his parents were at once impressed by his waddling gait.

The father was one of eight children and the mother one of four. All these were normal in stature and none apparently showed any bony abnormality. He was a short but sturdy child of 26 months. Height was $33 \cdot 5$ in. (85 cm.), upper segment 19.5 in. $(49.5 \mathrm{~cm}$.), lower segment 14 in. $(35.5 \mathrm{~cm}$.$) , span 31$ in. $(79 \mathrm{~cm}$.$) , and$ weight $27 \mathrm{lb}$. $(12 \cdot 2 \mathrm{~kg}$.). He showed gross rachitic deformities (Figs. 17a and b) as previously described for

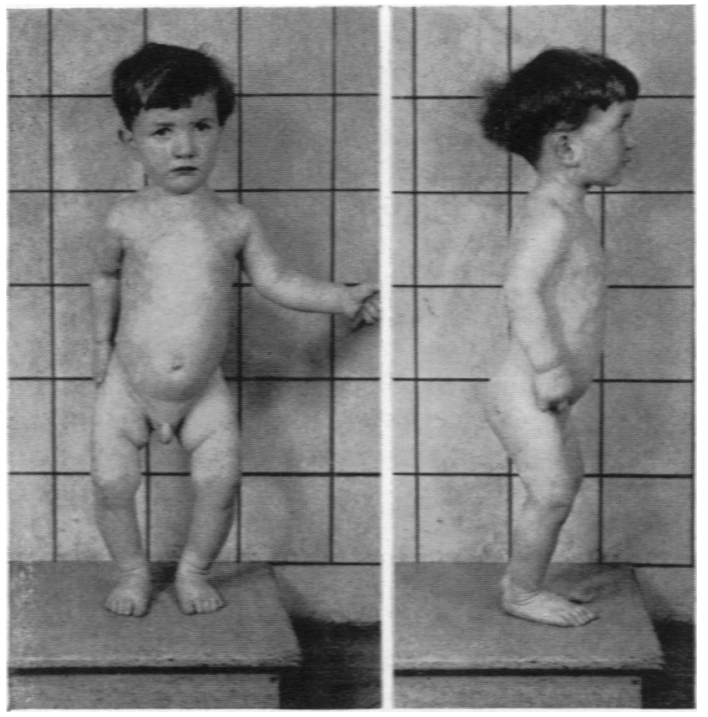

FK. 17a and b.-Christopher H. (Case 4).
Cases 1 to 3. His knee radiograph is shown in Fig. 18. The serum calcium was $10.4 \mathrm{mg} . / 100 \mathrm{ml}$., inorganic phosphorus $4 \cdot 9$ mg./ $100 \mathrm{ml}$., alkaline phosphatase 19 K.A. units $/ 100$ $\mathrm{ml}$., blood urea $24 \mathrm{mg}$./100 ml., plasma bicarbonate 21.3 $\mathrm{mM} / 1$. Routine examination and amino acid chromatography showed no abnormality. 24-hour urine calcium excretions were $44 \mathrm{mg}$. and $81 \mathrm{mg}$. Balance studies indicated that he was in positive calcium balance of approximately $100 \mathrm{mg}$. daily, which is perhaps rather less than would be

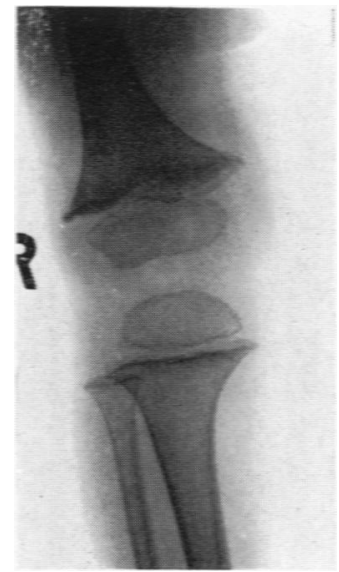

Fk. 18. - Christopher H. (Case 4). Radiograph of knee. expected in a normal grow-

ing child of this age. In view of the dramatic radiological improvement achieved by immobilization in the previous case it was decided to try the effect of steroids. Cortisone $50 \mathrm{mg}$. daily by mouth was given for three weeks and this was then reduced to $25 \mathrm{mg}$. daily for a further two months. There was no clinical or radiological improvement and this treatment was therefore discontinued.

Case 5. Gillian F. was first referred to Dr. R. E. Bonham Carter at the age of 2 months because an observant midwife had noticed some shortening and bowing of the humeri and femora and there was already some splaying and irregularity of the metaphyses.

She was born at home two weeks prematurely weighing 5 lb. 8 oz. (2.5 kg.). Both parents and her elder sister were of normal stature. Between 6 weeks and 3 months of age she was treated for a macrocytic anaemia of infancy and was given blood transfusions, iron, and folic acid. Since that time her peripheral blood picture had been normal. Her growth had always been severely retarded and walking was delayed until 21 months. Radiographs are shown in Fig. 19. She had been liable to repeated respiratory infections but in other respects her development has been normal.

When seen again at the age of 2 years, she was a small fairhaired girl height $25 \cdot 5$ in. (65 cm.), upper segment

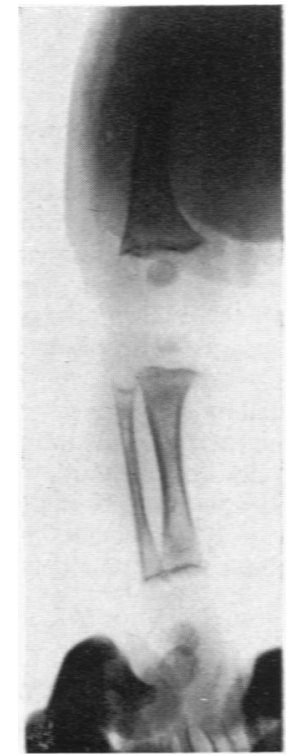

Frg. 19.-Gillian F. (Case 5). aged 3 weeks. Radiograph of lower limb. 


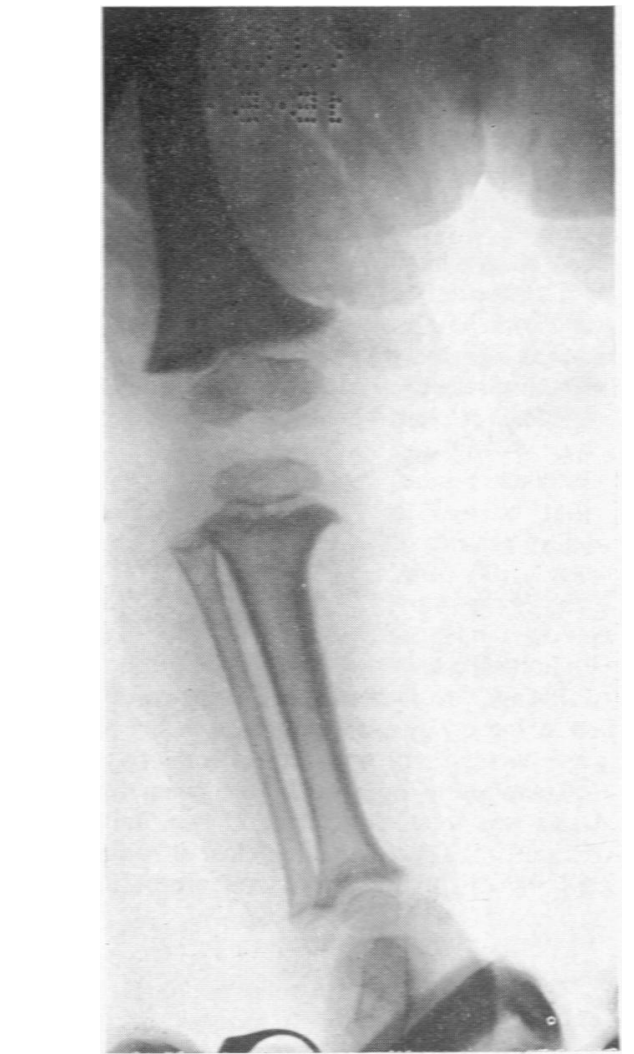

FIG. 20.-Gillian F. (Case 5). aged 2 years. Radiograph of lower limb.

15 in. (38 cm.), lower segment 10.5 in. $(27 \mathrm{~cm}$.$) , span$ $26.5 \mathrm{in}$. $(67 \mathrm{~cm}$.), weight $24 \mathrm{lb}$. (10.9 kg.). The proximal portions of her limbs were conspicuously shortened and there was much bowing of the femora. She had a waddling gait, lumbar lordosis, and expanded bone and rib ends. A Harrison's sulcus was present. Radiologically the metaphysial changes seen in Cases 1 to 4 were all present. The dilated femoral ends (Fig. 20), however, showed a more irregular and rather more deeply invaginated line of provisional calcification in the middle third of the metaphysis, than was seen in Cases 1 to 4 .

Serum calcium was $10.5 \mathrm{mg} .100 \mathrm{ml}$., inorganic phosphorus $5 \cdot 2 \mathrm{mg}$. $100 \mathrm{ml}$., and alkaline phosphatase $21 \cdot 6 \mathrm{~K}$.A. units $100 \mathrm{ml}$. Lirine examination revealed no abnormality and there was no abnormal aminoaciduria.

\section{Discussion}

Our studies suggest that the five children and the mother of one of them are suffering (or have suffered) from an identical bone dystrophy superficially resembling rickets. The normal biochemical data, however, exclude any form of rickets and the progress of the $\mathrm{x}$-ray appearances is also inconsistent. The two bone biopsies finally confirmed this distinction, for while they showed an abnormality like rickets in the cartilage of the growing bones, the trabecular bone in the adjacent part of the shaft was normal and, unlike the cartilage, was not undercalcified. The disease must, therefore, be a form of chondrodystrophy and not a generalized failure of calcification. This also would explain the normal plasma biochemical findings, calcium balances, and the remaining clinical and radiological appearances. Of practical importance is the failure to respond to vitamin $D$ in small (Cases 1 and 3 ) or large (Case 2) doses. It is clearly important to differentiate these cases from any form of rickets in order to avoid the dangers of vitamin $D$ intoxication which indeed was induced several times in Case 2 before the diagnosis was finally made. This hazard has also been reported by Evans and Caffey (1958).

Previous descriptions of this and of a related condition are summarized in the Table. It appears that the name metaphysial dysostosis has been applied to at least two distinct conditions. First, there is the very rare type described by Jansen (1934), which is perhaps better known in this country, as his case was also described in Fairbank's (1951) classic book. In this type the metaphysial lesions are gross and involve considerable adjacent bone. This superficially resembles the "rotting stump' appearance in primary or secondary hyperparathyroid osteodystrophy. There is no enlargement of the epiphysial plate to give a more truly rachitic appearance. Second, there is the type described by Schmid (1949) which seems much more common though not yet reported in this country. Our studies show that our five cases are all of the Schmid type and we strongly support their distinction from the Jansen type, as was also suggested by Weil (1957) and by Maroteaux and Lamy (1958).

The Schmid type is often hereditarily determined though the existence of frequent sporadic cases suggests the possibility of a high mutation rate. The genetic data so far available are consistent with inheritance by a dominant gene of high penetrance.

We would like to think that the mode of inheritance, and the fact that the manifestation of the disease is so homogeneous and chronic, both point to the probability that it is the result of an inborn error of metabolism. Unfortunately we have as yet no hints as to the disordered enzymic function in question. Clearly the disorder concerns calcification of metaphysial cartilage, all other processes of bone metabolism seeming to be normal. In vitro studies of samples of metaphysial cartilage, if obtainable, would be vitally important. The 
classical theory (Howland and Kramer, 1922) that its calcification must proceed normally, if the ion product of $\mathrm{Ca}$ and $\mathrm{P}$ in body fluids is adequate, is challenged by the existence of this disease.

We are especially intrigued by the healing of the metaphysial changes observed in Case 3 (Figs. 14-16) during a period of bed-rest. A similar improvement also followed immobilization in the case of Evans and Caffey (1958), and in Case 2 of Peterson (1962). The latter author, however, suggested that the vitamin $\mathrm{D}$ also given following an osteotomy was the cause of the improvement in the x-ray appearances and that he was dealing with a form of 'resistant rickets'. We do not agree with this interpretation. The healing during immobilization can also complicate the $\mathrm{x}$-ray diagnosis and may well be the reason why some other published cases show a milder metaphysial abnormality. The simplest explanation for the healing would be a mechanical one, namely that constantly abnormal epiphysial cartilage would grow better if not being constantly shattered by normal weight bearing. However, this cannot be the full explanation since the upper limbs of Case 3 also showed coincident temporary healing when she was immobilized. We wondered if the orthopaedic and other procedures leading to prolonged bed-rest in our Case 3 and in other published cases could have produced some form of adrenal response improving metaphysial growth. However, steroid therapy in Case 4 over a three-month period failed to alter the metaphysial disturbance.

The only therapy we can suggest at this stage is to limit activity as much as is reasonable during the growing period. We know the prognosis after this is excellent, for the older affected cases are all symptom free but of course of short stature. There seems no theoretical reason why their bones should differ from normal after fusion of the epiphyses.

In reviewing the published reports it became clear to us that the type Jansen metaphysial dysostosis was also a remarkably homogeneous disease entity. We have had no case of our own to study and with only four clear cases published (Table) it is too early to speculate on its causation. It is also obvious that other similar diseases apart from those of Schmid and Jansen remain for further identification and classification. Case 3 of Daeschner, Singleton, Hill, and Dodge (1960) was described as a possible mild type Jansen metaphysial dysostosis since the metaphysial lesions were much less marked than in the other cases. The case of de Toni (1960) was not a typical type Schmid for she had slender bones, multiple spinal defects, and the 'rachitic' changes were mild in most metaphyses while the femoral necks were almost completely destroyed. The boy of 12 years described by Schmidt, Becak, Becak, Soibelman, Queiroz, Lorga, Secaf, Antonio, and Carvalho (1963) bore some resemblance to that of de Toni but the metaphysial changes were more advanced perhaps because this child was older. Vaandrager (1960) described identical twin boys with generalized metaphysial irregularities which also showed marked lengthwise striations. The case of Kozlowski and Zychowicz (1962) showed abnormalities in the fingers, akin to those in type Jansen disease, and coarse metaphysial irregularities as in a type Schmid. However, the bones were long and slender, the epiphysial plates narrow, and the femoral necks normal. Case 1 of Peterson (1962) was puzzling. The published radiographs showed a

TABLE

PREVIOLS DESCRIPTIONS OF METAPHYSIAL DYSOSTOSIS. TYPES JANSEN AND SCHMID

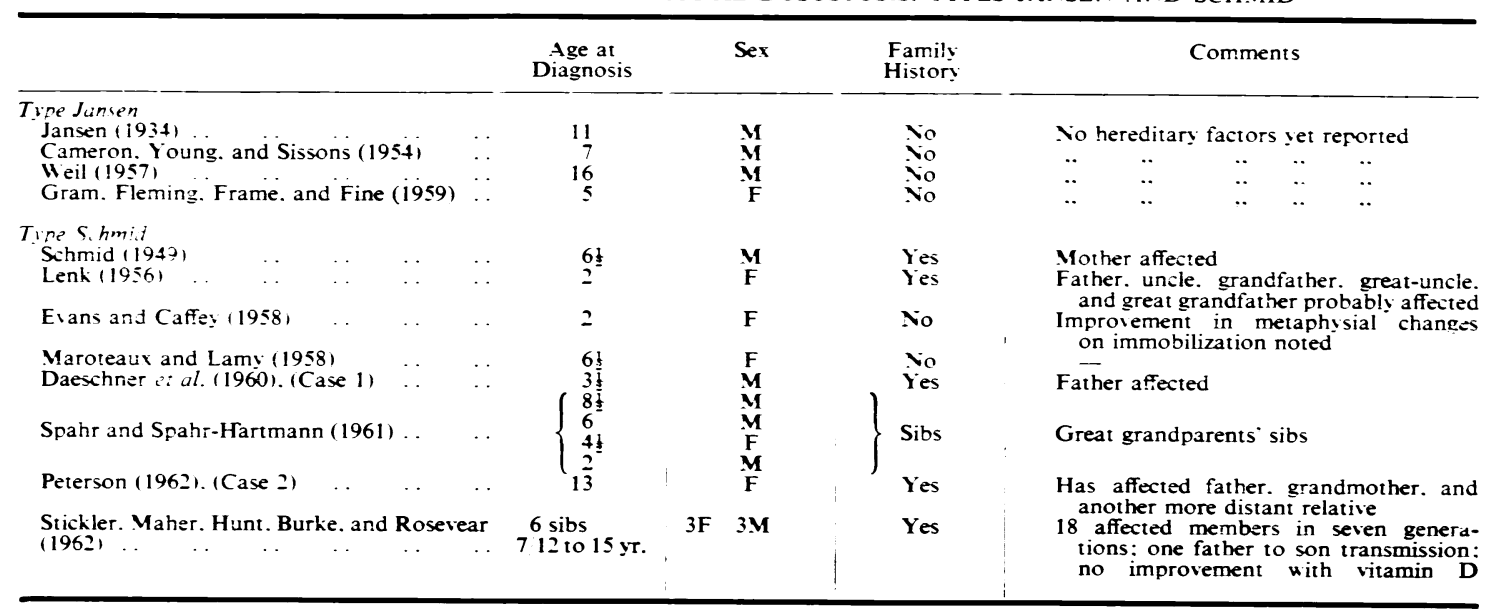


cystic lesion in a metaphysis, not a true rachitic appearance. It improved while vitamin $D$ was being given. The chief difference between the data published on this child and that of a type Jansen or Schmid metaphysial dysostosis was that Peterson's child was on the 90th percentile for height. All our cases and the cases referred to in the Table were grossly dwarfed.

We suggest that this may be a convenient moment to reconsider the nomenclature in this interesting group of diseases, and that it may be advisable now to restrict the use of the names metaphysial dysostosis type Jansen or type Schmid to those diseases described by the authors in the Table and by us in this paper.

\section{Summary}

Five new cases are described of metaphysial dysostosis, type Schmid. These cases with some of those already published form a group clearly distinguishable from the "metaphysial dysostosis" described by Jansen.

The evidence from all these cases strongly suggests that the Schmid type is hereditary and determined by a dominant autosomal gene of high penetrance and high mutation rate.

An associated biochemical disorder has not been discovered. No treatment is suggested, though in one case we have confirmed the remarkable effect of immobilization in improving the radiological appearance of the metaphyses. Vitamin $D$ has no beneficial effect on the disease.
It is important to distinguish this disease from the various forms of 'resistant rickets' which it so closely resembles clinically and radiologically.

\section{REFERENCES}

Anderson. J. (1955). A method for estimating $\mathrm{Tm}$ for phosphate in man. J. Physiol. (Lond.), 130. 268.

Cameron. J. A. P., Young, W. B.. and Sissons, H. A. (1954). Metaphysial dysostosis. J. Bone Jt Surg., 36B, 622.

Daeschner. C. W., Singieton, E. B., Hill, L. L., and Dodge W. F. (1960). Metaphysial dysostosis. J. Pediat., 57, 844.

Evans. R.. and Caffey. J. (1958). Metaphysial dysostosis resembling vitamin D-refractory rickets. A.M.A. Amer. J. Dis. Child., 95. 640.

Fairbank. T. (1951). Metaphysial Dysostosis. In An Atlas of General Affections of the Skeleton, p. 85. Livingstone. Edinburgh

Gram, P. B.. Fleming. J. L., Frame. B., and Fine, G. (1959). Metaphyseal chondrodysplasia of Jansen. J. Bone Jt Surg., 41 A. 951.

Howland, J., and Kramer, B. (1922). Factors concerned in the cakcification of bone. Trans. Amer. pediat. Soc. 34, 204.

Jansen. M. (1934). Uber atypische Chondrodystrophie (Achondroplasie) und ūber eine noch nicht beschriebene angeborene Wachstumsstōrung des Knochensystems: Metaphysāre Dysostosis. Z. orthop. Chir., 61, 253.

Kozlowski. K., and Zychowicz, C. (1962). Metaphyseal dysostosis of mixed type in a female child. Amer. $J$. Roentgenol 88, 443.

Lenk, R. (1956). Hereditary metaphyseal dysostosis. ibid., 76. 569.

Maroteaux. P.. and Lamy, M. (1958). La dysostose metaphysaire. Sem. Hôp. Paris. 34ii, 1729.

Peterson. J. C. (1962). Metaphyseal dysostosis: questionably a form of vitamin D-resistant rickets. J. Pediat., C0, 656.

Schmid, F. (1949). Beitrag zur Dysostosis enchondralis metaphysaria. Mschr. Kinderheilk., $97,393$.

Schmidt, B. J., Becak, W., Becak. M. L.. Soibelman. I., Queiroz. A. da S.. Lorga. A. P., Secaf. F.. Antonio, C. F., and Carvalho, A. de A. (1963). Metaphyseal dysostosis. J. Pediat., 63. 106.

Spahr, A.. and Spahr-Hartmann, I. (1961). Dysostose métaphysaire familiale. Helv. paediat. Acta, 16. 836.

Stickler. G. B.. Maher. F. T.. Hunt. J. C.. Burke. E. C. and Rosevear, J. W. (1962). Familial bone disease resembling rickets (Hereditary metaphysial dysostosis). Pediatrics. 29. 996.

de Toni, E. (1960). Su di un caso di malattia di Schmid (Disostosi metafisaria). Minerva pediat.. 12, 1191.

Vaandrager, G.J.(1960). Metafysaire dysostosis? Ved. T. Geneesk. 104. 547.

Weil. S. (1957). Die metaphysāren Dysostosen. Z. Orthop.. 89 1. 